\title{
Endeudamiento "saludable", empoderamiento y control social
}

\author{
Alejandro Marambio Tapia \\ Universidad Católica de Talca, Maule, Chile. \\ Email: amarambio@ucm.cl
}

\begin{abstract}
Resumen: La interpretación del neoliberalismo como gubernamentalidad se basa en considerarlo una estructura dinámica que adapta y adopta las particularidades témporo-espaciales. Es a través de este proceso que el neoliberalismo logra cooptar las realidades de los individuos, su construcción e interpretación, para proponer e imponer sutiles formas de control (BarryyOsborne, 2013). Al entrar al circuito de la normalización y del sentido común o del "actuar sensato”, la deuda se transforma en un mecanismo de control, por los efectos que tiene en la vida material y la subjetividad de las personas.Este artículo se basa entrevistas con encargados de programas de educación financiera de agencias estatales y entrevistas en profundidad con jefes y jefas de hogar sobre su vida económica diaria, sus significados y la subjetividad producida en torno a ello. Políticas públicas tales como la educación financiera se orientan a producir una subjetividad atada al "derecho a pagar" y al derecho a endeudarse "saludablemente". Ambas actividades son anunciadas como una especie de “empoderamiento social” y con discursos de movilidad social individual, pero finalmente son formas de control.
\end{abstract}

educación financiera

Palabras clave: Deuda, gubernamentalidad, subjetividad, neoliberalismo,

\section{"Healthy" indebtedness, empowerment a nd social discipline}

\begin{abstract}
The view of neoliberalism as governmentality lies on its dynamic structure that shapes and adopts the space-time features where it is set. Through this process, neoliberalism is able to co-opt the "real life" of individuals, including their construction and interpretation. This way, neoliberalism proposes and imposes subtle forms of control (Barry, Osborne, \& Rose, 2013). By entering the circuit of normalisation and common sense or "acting wisely", debt becomes a control mechanism, due to its effects over the material life and the subjectivity of individuals. This article is based on interviews with managers of financial education state programmes and in-depth interviews with heads of households about their daily economic life, their meanings and the subjectivity around them. Public policies such as financial education are aimed at producing subjectivities tied to the "right to pay" and the right to borrow "healthily". Both activities are announced as a kind of "social empowerment”, with discourses of individual social mobility, but ultimately, they just are forms of control.
\end{abstract} education

Keywords: Debt, governmentality, subjectivity, neoliberalism, financial 


\section{Dívida “saudável”, empoderamento e controle social}

Resumo: A interpretação do neoliberalismo como governamentalidade baseiase em considerá-la uma estrutura dinâmica que se adapta e adota as características espaço-temporais. É através deste processo que o neoliberalismo consegue cooptar as realidades dos indivíduos, sua construção e interpretação, para propor e impor formas sutis de controle (Barry, Osborne e Rose, 2013). Ao entrar no circuito de normalização e senso comum ou do "agir com sensatez", a dívida se torna um mecanismo de controle, devido aos efeitos que ela tem sobre a vida material e a subjetividade das pessoas. Este artigo baseia-se em entrevistas com diretores dos programas de educação financeira de agências estatais e entrevistas em profundidade com chefes e chefas de família sobre sua vida econômica diária, seus significados e a subjetividade em torno deles. As políticas públicas, como a educação financeira, visam produzir uma subjetividade ligada ao "direito a pagar" e ao direito de se endividar "com saúde". Ambas as atividades são anunciadas como uma espécie de "empoderamento social” e com discursos de mobilidade social individual, mas, em última análise, são formas de controle.

Palavras-chave: Dívida, governamentalidade, subjetividade, neoliberalismo, educação financeira

$* * *$

\section{Introducción}

El neoliberalismo es una ideología que organiza un conjunto de principios expresados en una bien constituida receta de políticas públicas, y que finalmente determina la articulación entre economía, sociedad y política (Garretón, 2012). La prevalencia del mercado y su articulación de intereses individuales resulta problemática para organizar la sociedad como una entidad y también presenta problemas para la integración social y la movilización colectiva. El neoliberalismo no es una estructura monolítica ni completamente externa a los individuos. Así como neoliberalismo chileno ha ido transformándose (ver French-Davis, 2003; Muñoz, 2007; Garretón, 2012) tampoco se pueden negar las particularidades locales del neoliberalismo en Europa o Asia, y su hibridación (Peck, 2004).

No obstante, sí se podría afirmar que el neoliberalismo se aplicó "puramente" en Chile. Primero, por las condiciones de laboratorio, que generó, primero, el golpe militar conservador y reaccionario de 1973 que eliminó velozmente cualquier posibilidad de oposición política, y luego,por la aparición de los tecnócratas Chicago Boys -un grupo de economistas formados al alero de Martin Friedman-, que, al hacerse cargo de la conducción económica reformista del nuevo régimen, se consolidaron como alternativa al capitalismo nacional de la derecha tradicional. Aún este neoliberalismo "puro" de los 1970s fue mutando hacia una versión "corregida-democrática”. Como resultado, los momentos más conservadores de la historia reciente de Chile se vivieron mientras la economía se liberalizaba, y aunque sin aumentar el número de emprendedores, sino que más bien se constituyendoun capitalismo jerárquico (Schneider, 2013), con una con- 
centración del capital en grandes grupos económicos y la formación de mercados oligopólicos, característica similar a otras economías de Latinoamérica.

Actualmente, el capitalismo chileno ha entrado en una fase de financiarización, proceso que ha sido descrito en varias escalas, incluyendo estados y hogares. La idea subyacente en todas estas descripciones es que el dinero y las finanzas se transforman en aspectos dominantes en las sociedades del capitalismo tardío. La crisis financiera de 2007-2008 sirvió para validar el concepto y ponerlo tanto en la agenda académica como mediática (French et al, 2011). La financiarización es usada para subrayar la preponderancia que adquiere el sector financiero en la economía y en la sociedad, idea que no es nueva y que puede ser encontrada en Marx (Miliband, 1988) y en Weber en su Historia Económica General (2012). Lo original es el postulado de que proceso situado en la esfera macroeconómica permea la forma de administrar empresas, liderar Estados y también la vida diaria de hogares e individuos, no solo a través de la penetración de instrumentos financieros, sino que insertando valores y significados.

Una de las maneras de entender la financiarización es situar este proceso en la vida diaria financialisation of everyday life, desde un enfoque más bien sociocultural (Martin, 2002). Estaperspectiva parece más útil para comprender los procesos de expansión de la deuda y de la justificación de la educación financiera. En cierta manera, ayuda a contextualizar los objetivos económicos tras la expansión del crédito en Chile: (1) aumentar las ventas del sector retail y (2) aumentar la venta de bienes y servicios de consumo, con dos objetivos sociales: (a) la reproducción ideológica del nuevo tipo de sociedad, la sociedad de consumidores, ofreciendo a los sujetos formas no conflictivas de asegurar sus metas individuales y (b) dar un sustento empírico a la narrativa de la "democratización del consumo" y la inclusión social. La financiarización de la vida diaria viene a considerar al crédito en dos dimensiones: una material, como presente en las prácticas de organización presupuestaria familiar y otra sustantiva, en relación con la producción de nuevas subjetividades.

La financiarización de la vida diaria se relaciona con la subjetividad neoliberal a través de la forma como los hogares incorporan (o deberían incorporar) el riesgo a su planificación doméstica, y como los tópicos financieros se hacen (o deberían hacerse) familiares para todos. Elretiro del Estado y la desregulación de los mercados apuntan a la autogestión de los individuos. Estos individuos deben ser responsables, asiduos al cálculo y reflexivos en sus asuntos financieros cotidianos (Marron, 2014).La idea de gubernamentalidad (Foucault, 2005) intenta develar el verdadero espíritu del capitalismo en tanto sistema productor de sujetos, más que de bienes y servicios. Estos sujetos son disciplinados, gobernados por el sistema a través de dispositivos de control y poder tan sutiles que se hacen casi invisibles para los individuos. El endeudamiento, a través de una visión no económica del mismo, sería uno de ellos. Además, se debe considerar el rol de los individuos y su capacidad de agencia, con mayor o menor entusias- 
mo, con mayor o menor deliberación, en la reproducción de los distintos tipos de neoliberalismo. Desde esa forma, la subjetividad neoliberal, con matices, es ubicua, como la noción de poder foucaultiana.

La interpretación del neoliberalismo como gubernamentalidad se basa principalmente en considerarlo una estructura dinámica que adapta y adopta las particularidades témporo-espaciales. Es a través de este proceso que el neoliberalismo logra cooptar las realidades de los individuos, su construcción e interpretación, para de esta forma proponer e imponer sobre ellos sutiles formas de control (Barry y Osborne, 2013), que finalmente se ejecutan como dispositivos de autocontrol, como la deuda, y que ya no dependen de una entidad única, sino que más bien son llevados consigo por cada de unos los individuos, ejerciendo el poder a distancia (Foucault, 1991). Al entrar al circuito de la normalización y del sentido común o del "actuar sensato”, la deuda se transforma en parte de los mecanismos de control, porlos efectos que tiene en la vida material de las personas, ya sea para acceder a bienestar o para evitar la exclusión social.

Este es el punto de partida para explicar el ejercicio de poder que ejerce el neoliberalismo desde una perspectiva individual y biológica (Foucault, 2007), y desacralizar la dominación formal-legal como un único instrumento de control.La forma cómo la economía es manejada es fundamental para entender cómo aquellos que ejercen el poder se orientan -a veces sutilmente- a dominar las conductas de aquellos que no están en el poder, incluso a través de la ilusión de una libertad para elegir. En este contexto, en el Norte Global, se plantea que tras décadas de financiarización el ‘gerente de sí mismo’ cuyo auge se encontraba en los 1970s se ha transformado en el 'hombre endeudado' (Lazzarato, 2012). La deuda sería el núcleo del capitalismo contemporáneo, constituyéndose además como un hecho político más que económico. La deuda es usada por gobiernos y empresas para ejercer control sobre los individuos, elaborando una variedad de arreglos sociales y financieros para incentivar y hacer digerible el uso y acceso al crédito.Lazzarato propone una visión envolvente y comprehensiva de la sociedad, cuya base no estaría en el intercambio, económico o simbólico, sino más bien en el crédito y la asimetría que genera la deuda, que histórica y teoréticamente preceden las dinámicas puras de producción y trabajo asalariado. En ese contexto, enfatiza que la deuda, si bien es una relación económica, es inseparable de la producción de un sujeto deudor con su correspondiente moralidad.

En el caso chileno, la deuda ha sido siempre considerada -en general los problemas económicos- como un asunto individual y privado. Así se refuerza a través de las instancias de educación financiera implementadas por el Estado y el mercado. Este refuerzo de la responsabilidad individual de la deuda está en línea con el sujeto neoliberal que debe ser capaz de dar cuenta de sus actos, ser responsable, pero a la vez tomar riesgos (Marron, 2014), y que, a través de acciones como el endeudamiento, es gobernado a través de sus conductas (Foucault, 2005). En el último tiempo, se ha generado novedosa y consistente literatura que parte del presupuesto de la 
deuda y el crédito como relaciones sociales y analiza situadamente los circuitos del crédito (Barros, 2011; Ossandón, 2013; Ossandón et al, 2017), las orientaciones individuales y culturales del uso de la deuda (González, 2015; 2017) y los significados de la deuda para grupos concretos de la sociedad chilena (Pérez-Roa, 2014; Marambio-Tapia, 2017). Siendo este artículo tributario de estas perspectivas, en particular, nos interesa desarrollar la idea de que las políticas públicas neoliberales se orientan a producir una subjetividad atada el derecho a pagar y el derecho a endeudarse "saludablemente". Entonces, ambas actividades son anunciadas como una especie de “empoderamiento social” y con discursos de movilidad social individual, pero son finalmente formas de control. En la siguiente sección, presento brevemente los aspectos metodológicos y las fuentes de la investigación que sustenta este artículo; en la tercera, entrego los resultados concernientes a los contenidos, orientaciones y objetivos de los programas de educación financiera estatales en Chile. En el siguiente acápite, me refiero al impacto tanto de la deuda como de las actividades de educación financiera en los hogares de bajos y moderados ingresos. Finalmente, organizo la discusión de los datos situando la educación financiera como una estrategia nueva dentro de los dispositivos de control que ha ejercido el neoliberalismo, y rescatando las particularidades del sujeto endeudado en Chile, y sus posibles caminos políticos.

\section{Metodología}

Este artículo se basa en datos recogidos en una docena de entrevistas con encargados de los programas de educación financiera de agencias estatales de Chile, tales como Banco Central, Sernac (Servicio Nacional del Consumidor), Fosis (Fondo de Solidaridad e Inversión Social) y SBIF (Superintendencia de Bancos e Instituciones Financieras), y sus organizaciones asesoras. Además, considera entrevistas en profundidad acerca de las prácticas económicas de los jefes y jefas de hogar en el contexto de su vida diaria, sus significados y la subjetividad en torno a ello. Estas 46 entrevistas en profundidad se realizaron en la ciudad de Santiagoy Copiapó, 800 kilómetros al norte de la capital chilena Parte de los jefes y jefas de hogar entrevistados participaron en los programas de educación financiera, en particular de Fosis, y algunas de dichas actividades fueron observadas en terreno. El discurso y alcance de la educación financiera fue también investigada a través del análisis del material impreso y audiovisual elaborado por los programas, y principalmente, a través de la participación de cursos en línea.

En el caso de las entrevistas con los jefes y jefas de hogar, la investigación se centró en hogares de ingresos bajos (entre 68 mil y 187 mil pesos de ingreso familiar per cápita) y moderados (entre 188 mil y 350 mil pesos de ingreso familiar per cápita), en particular en dos subgrupos: el primero, trabajadores del proletariado de servicios (trabajadores en funciones de rutina no manual en supermercados, tiendas por departamento y ocupaciones bajas de empresas de servicios), y el segundo, micro-emprendedores 
de baja calificación, que reciben subsidios del Estado para iniciar y/o formalizar su actividad productiva-comercial. Además, elaboré un set de micronarrativas socioeconómicas de los entrevistados, denominadas trayectorias de deuda, pero más amplia, considerando las implicancias sociales y familiares de lo económico. Gracias a este material pude analizar las implicancias de la deuda en la construcción de identidades de clase y como dispositivo de control subjetivo.

\section{Educando al deudor "saludable"}

Uno de los efectos de la financiarización de los hogares es precisamente la emergencia de la educación financiera como un contenido de política pública. Mi punto es que la educación financiera, al descansar sobre la noción de homo economicus y una racionalidad formal, niega el conocimiento adquirido por los hogares en el mismo contexto de la financiarización. A su vez, ignora la función estructural de los proveedores de crédito, ya que, como hemos subrayado, el objetivo final es la transferencia de responsabilidad y autocontrol a los individuos. Para llegar a ello, despliega las comprensiones ortodoxas del comportamiento del consumidor y la teoría de la acción racional. El tratamiento que se hace del endeudamiento como un problema psicosocial asociado al consumismo, que puede y debe ser tratado, presenta el comportamiento económico asociado al uso del crédito como carente de fundamentos morales y sociales. Se centra más bien en un consumidor irreflexivo que debe ser educado para asumir su responsabilidad como sujeto de crédito. Finalmente, estas construcciones excluyen los aspectos estructurales desiguales que contribuyen a la producción de la subjetividad y materialidad del sujeto endeudado.

Las autoridades económicas globales han reconocido a Chile como pionero en la inclusión financiera de grupos de ingresos bajos. Perú, Colombia y Ecuador han focalizado sus esfuerzos en administrar cursos de educación financiera en áreas rurales para tímidamente intentar una bancarización. Brasil, por ejemplo, muestra una creciente penetración de instrumentos financieros gracias a los programas de transferencias monetarias y al despliegue de bancos (Müller, 2014).

Sin embargo, es necesario hacer una distinción entre la introducción de instrumentos financieros y una casi completa dependencia en las prácticas financieras para el manejo financiero doméstico de los hogares. En Chile, durante los 1970s y los 1980s, en el inicio del proceso de liberalización financiera, la bancarización estuvo orientada hacia los segmentos altos y medios altos, liderada por bancos. A contar de los 1990s, ya en democracia, se produjo una nueva ola de inclusión financiera, esta vez liderada por supermercados y tiendas por departamento. Esta 'retailización' se orientó a segmentos medios bajos y bajos, especialmente aquellos que no habían tenido acceso al crédito hasta ese momento, y se complementó con la posición dominante de estos grandes retailers en la provisión de puestos de trabajo para el nuevo proletariado de servicios, en el acercamiento a la 
sociedad de consumo a dichos grupos y en la oferta de todo tipo de instrumentos financieros personales tales como tarjetas de crédito, préstamos de consumo, avances en efectivo, financiamiento automotriz, bodas y vacaciones, seguros, etc. En mucha menor medida, instrumentos de capitalización y ahorro. Fue una financiarización principalmente crediticia. Al mismo tiempo, educación, vivienda, salud y pensiones se financiarizaron. En este paisaje, el requerimiento neoliberal requiere de individuos que consideren sus presupuestos de forma ordenada, disciplinada y con pundonor. La educación financiera viene a cerrar la brecha de aquellos que no tienen gran comprensión o interés en el ámbito financiero.

La invasión y conquista del paradigma neoliberal en la empresa y el Estado se advierte en conceptos tales como la gestión por competencias, la educación en competencias, el ideal de concursabilidad, la estructura político-administrativa de principal-agente, el nacimiento del usuario-cliente, la evaluación de proyectos, a través de la metodología del marco lógico, y la transformación de los trabajadores en poseedores de capital humano. A esta lista de dispositivos que de una u otra forma buscan traspasar responsabilidades estructurales a los individuos, nos interesa sumar las estrategias estatales de educación financiera.

La definición de la OCDE (2014)sobre la educación financiera incluye la comprensión de conceptos y de los riesgos, desarrollo de habilidades y confianza para ver oportunidades, y el beneficio a familias y al sistema financiero, por igual. En Chile, el Estado advierte que el crecimiento y estabilidad económica ha optimizado en general las condiciones materiales de los individuos, pero también ha incorporado una serie de complejidades. Se presenta un escenario de oportunidades, pero también de riesgos. Los actores individuales, no obstante, deben ser capaces de enfrentar los desafíos. Para ello, se plantea desde el Estado, hay que ser más responsable para endeudarse y que como consumidores tenemos “deberes y derechos”, un lugar común para el SERNAC, sólo ampliado por particulares iniciativas queintentan agregar un sentido a la acción instrumental económica o "los valores detrás de los contenidos”, como lo describió una encargada de dicho programa en particularRespecto a los oferentes del crédito, el Estado asume que tienen "reglas claras” y que su responsabilidad es hacer una evaluación informada y detenida, como lo indicaron los encargados de la SBIF y el Banco Central

La Plataforma Nacional de Educación Financiera en Chile fue una mesa de coordinación pública- privada que nació en 2014 para articular acciones de manera interna y abogar por la creación de una Estrategia Nacional de Educación Financiera a nivel estatal, finalmente concretada en 2018 (Comisión Asesora para la Inclusión Financiera, 2018). Participaron en ella agencias públicas del poder ejecutivo y autónomo, y algunos organismos del tercer sector, sin considerar bancos u otras instituciones financieras ni organizaciones ciudadanas. Su diagnóstico se basó en la constatación de una masiva bancarización junto con bajos conocimientos para realizar operaciones financieras, en términos de calculabilidad y operatividad, 
basado en datos de la Encuesta de Protección Social de la Subsecretaría de Previsión Social. Además, se observó un déficit en prácticas estandarizadas sobre el manejo del dinero, tales como herramientas de planificación, y en la terminología y uso del crédito. La amalgama de agencias involucradas se dirige a diversos sujetos-usuarios con distintos grados de universalidad: consumidores, micro-emprendedores, clientes bancarios y también a la estructura del sistema financiero. No obstante, el discurso y praxis unificada apunta a corregir acciones individuales ante el riesgo que dichas 'malas prácticas’ impacten la estructura financiera y económica, tal como ocurrió en la crisis sub-prime en Estados Unidos, cuando la responsabilidad de la crisis fue dirigida desde los actores institucionales hacia los individuales. Desde este punto de vista,la crisis evidenció una gran expansión de las finanzas, pero a costa de complejizar los productos y de poner la responsabilidad en los contratos individuales, ante lo cual hay poca comprensión de lectura y carencia de habilidades. La Educación Financiera sería un instrumento de política pública que llevaría a reducir brechas de información y habilidades. En el caso particular de Banco Central, se señala que el verdadero objetivo de la educación financiera no debiera ser tanto el aprendizaje de formas de cálculo o el funcionamiento de instrumentos financieros, y más la internalización de “actitudes, conductas y prácticas” que señalen el camino a una incorporación "sana” y "saludable” al mundo financiero, a través de buenas decisiones.

El Fondo de Solidaridad e Inversión Social (Fosis), también participa de la estrategia de Educación Financiera. Fosis implementa su programa de educación financiera, sobre la base de una metodología que incluye manejo de presupuesto, endeudamiento responsable, ahorro e inversión. Se trabaja con familias “Fosis”, es decir, con familias técnica y legalmente catalogadas como pobres. A la fecha 5.800 familias han sido beneficiarias, incluyendo más 10.000 estudiantes con el juego “Tú decides”. De acuerdo a la encargada, es “un éxito”ya que un 77 por ciento de las personas mejoraron sus conocimientos financieros y un 64,3 por ciento mejoró su índice de habilidades, de acuerdo los datos del mismo Fosis (2015). Sin embargo, sólo un 3 por ciento de los participantes declaró haber disminuido su deuda. De acuerdo a lo observado de manera directa, algunos de los participantes declararon “mejorar su autoestima” al saberse capaces de enfrentar tópicos financieros y con ello, ser capaces de asumir más responsabilidades en su propio desarrollo.

\section{Lidiando con deudas: arreglos financieros, morales y sociales}

En la sección anterior, exploramos como es el Estado quien prescribe ideales de deudores competentes como proyectos coherentes y factibles de alcanzar para los individuos. En este sentido resulta irrelevante una distinción entre quienes tienen deuda y quienes no tienen. La deuda gobierna tanto a deudores y a no deudores. La regularidad del endeudamiento 
nos lleva a concluir que la condición de deudor o no deudor podría tornarse irrelevante, puesto que aún quienes no lo sean en un momento determinado, puede que sí lo hayan sido en los últimos tres meses o lo sean durante los tres siguientes. Incluso quienes le dan un contenido amenazante al crédito y procuran evitar lo a toda costa, se autoimponen una ética de la disciplina muy importante a través de la deuda.

"Odio deber algo, no uso ninguna tarjeta ni nada por el estilo, y a veces he tenido que pedir plata para comprar algo que necesita mi hija para hacer tareas en el colegio, y justo toca antes de que me paguen. En ese caso, le pido plata prestada a un compañero, y apenas me pagan mi sueldo, voy y le pago, y le pido que me haga una mosquita (firma) en mi cuaderno, para que quede claro que salí de esa deuda”,

Mujer, 40, empleada administrativa de gran empresa de telecomunicaciones.

En general, la mayoría de las familias que tiene deuda tiende a aumentar su deuda en términos relativos. Más allá de las cifras, existe una disposición a endeudarse luego de obtener algún logro profesional o laboral, por ejemplo, un ascenso. Muchas personas declaran que sus “desórdenes financieros” se inician al tener más dinero disponible para gastar.

"Me cambiaron de puesto en la oficina y con eso empecé a ganar más plata... y también me empecé a endeudarme más, en un principio era porque quería comprarme cosas que antes no podía, pero luego sentí que estaba todo desordenado",

Mujer, 26, administrativa de empresa de seguros.

Personas que declaran con certeza no querer endeudarse, lo explican porque al ganar poco dinero, eso las obliga a ser austeras y ser muy estrictas con la organización del dinero. Otras, en cambio, registran algún evento traumático con las deudas en el pasado y prefieren mantenerse al margen para evitar dicho malestar, no obstante, la diferencia aquí es la carencia de una actitud "condenatoria”, y, por tanto, podrían eventualmente acercarse al “mundo del crédito”, pero con mayor conocimiento del sistema.

Los usuarios del crédito usualmente contradicen los supuestos de la microeconomía ortodoxa, sobre información, "racionalidad económica” y cálculo, que está en la base de los programas de economía financiera, como se detalla en la Tabla 1. También contradicen el marco de rendición de cuentas del ciudadano neoliberal al ser irresponsables en la gestión financiera. Por ejemplo, ¿qué sucede cuando las personas no tienen en cuenta la deuda que ya poseen antes de obtener un nuevo préstamo, o cuando prestan atención sólo a los pagos mensuales en lugar del precio final que terminarán pagando por un bien?El momento de la adquisición de la deuda podría enmarcarse en términos de al menos dos escenarios, restricciones y ansiedad. La restricción enmarca la adquisición de deudas porque, a pesar de las 
narrativas de una abrumadora libertad de elección, en este contexto las limitaciones sociales de un historial de bajos ingresos o mal historial de crédito, no dejan otra opción que el crédito de alto costo. De esta forma, la libertad de elección es exigua ante la carga de responsabilidades contraídas a cambio.

El enfoque "psicológico" de la Educación Financiera, expresado en los contenidos educativos de SBIF y SERNAC, y los cursos en línea de Educación Financiera, enfatiza cómo los hábitos, las preferencias y el carácter impactan la manera en que las personas manejan su dinero. La suposición habitual aquí es que es necesario entregar a las personas las herramientas y el conocimiento para ayudar a informar sus decisiones económicas, hábitos y estrategias personales con el fin de ser un "consumidor crítico, responsable y eficiente” (Denegri et al., 2014; Fundación Capital, 2015). La gratificación a corto plazo parece sensata a los individuos en la medida en que el crédito está más disponible que antes y no hay "gratificación” en el ahorro formal, porque el interés pagado es considerablemente menor, y algunas cuentas incluso cobran una tarifa.

\section{Tabla 1}

\section{Resumen de las prescripciones de la Educación Financiera y de las racionalidades financieras de los hogares}

\begin{tabular}{|c|c|c|}
\hline & Marco de la Educación Financiera ${ }^{1}$ & Racionalidad de los hogares ${ }^{2}$ \\
\hline $\begin{array}{l}\text { Administración } \\
\text { del dinero }\end{array}$ & $\begin{array}{l}\text { Temporalidad de instrumentos financieros } \\
\text { Planificación es riqueza } \\
\text { Emociones no pueden guiar las compras } \\
\text { Supuestos de la elección racional } \\
\text { Autocontrol es necesario } \\
\text { Siempre mantener registros para así poder } \\
\text { dar cuentas si es requerido } \\
\text { Evitar compulsión y desorden }\end{array}$ & $\begin{array}{l}\text { Finanzas regidas por la temporalidad de os } \\
\text { hogares. } \\
\text { Crédito no es neutral y puede ser bueno o } \\
\text { malo } \\
\text { Aprender a lidiar con el crédto es necesario } \\
\text { Autocontrol es usualmente necesario } \\
\text { Compulsión coexiste con restricciones y } \\
\text { subsistencia }\end{array}$ \\
\hline $\begin{array}{l}\text { Cuentas } \\
\text { corrientes y } \\
\text { otras cuentas }\end{array}$ & $\begin{array}{l}\text { El uso de instrumentos financieros ayuda a } \\
\text { controlar el dinero } \\
\text { Un bueno consumidor sabe escoger los } \\
\text { instrumentos mejor dieñados para él }\end{array}$ & $\begin{array}{l}\text { Muchos instrumentos financieros } \\
\text { provocan desorden y cesación de pagos } \\
\text { No hay acceso a todos los instrumentos. }\end{array}$ \\
\hline $\begin{array}{l}\text { Pago de } \\
\text { cuentas }\end{array}$ & $\begin{array}{l}\text { Mensualmente, a tiempo } \\
\text { Siempre separar dinero por adelantado } \\
\text { para pagar } \\
\text { Usar métodos de pago automático para } \\
\text { evitar el no pago }\end{array}$ & $\begin{array}{l}\text { Diversos métodos: cada dos meses, } \\
\text { altemando distintas cuentas, prionzando } \\
\text { unas sobre otras, irregulamente si los } \\
\text { ingresos son variables. } \\
\text { Jovenes usan pago automático. Otros lo } \\
\text { evitan porque quieren reservarse la opción } \\
\text { de no pagar en alguna oportunidad. } \\
\text { Muchosnotienen acceso a pago aumático }\end{array}$ \\
\hline Uso del crédito & $\begin{array}{l}\text { El crédito está presente en nuestros } \\
\text { grandes eventos en la vida. } \\
\text { Cotizar el crédito con las mejores } \\
\text { condiciones } \\
\text { Considerar el crédito como una inversión }\end{array}$ & $\begin{array}{l}\text { Crédito tiene diveras onentaciones: } \\
\text { proyecto, consumo conspicuo, consumo } \\
\text { ordinano, "fondo" contra emergencias. } \\
\text { Cotización del crédito es generalmente } \\
\text { imposible por falta de acceso real a } \\
\text { opciones }\end{array}$ \\
\hline Pago de deudas & Siempre a tiempo, para evitar multas. & $\begin{array}{l}\text { Generalmente a tiempo. Sin embargo, en } \\
\text { ocasiones pagar es imposible } \\
\text { inconveniente. }\end{array}$ \\
\hline $\begin{array}{l}\text { Prácticas } \\
\text { diarias }\end{array}$ & $\begin{array}{l}\text { Elaborar una lista de compras, llevar } \\
\text { registro y control de gastos, revisar boletas } \\
\text { y cuantas, estar atento a gastos } \\
\text { extraordinarios. }\end{array}$ & $\begin{array}{l}\text { Combinar instrumentos financieros, estar } \\
\text { atento a ofertas, separar dinero para gastos } \\
\text { esenciales, llevar un control de gastos } \\
\text { general. }\end{array}$ \\
\hline
\end{tabular}

Fuente: elaboración propia 
La historia de la deuda reciente en los hogares chilenos es desarrollada a partir de las últimas dos décadas, cuando los jefes de familia percibieron un aumento masivo en el acceso al crédito con distintas narrativas. Sus descripciones de la expansión crediticia se construyen a partir de las experiencias de quienes ya eran jefes de familia, de quienes trabajaban o aún trabajan en empleos vinculados al crédito, y de quienes, como adolescentes, prestaban atención a la forma en que sus padres tomaban decisiones sobre el presupuesto familiar. En esas narrativas, hubo un antes, donde la norma era aceptar lo que solamente un ingreso podría comprar. El ahora, aunque la vida material "es mejor", también viene con más riesgos y sanciones, debido al endeudamiento.Las aspiraciones materiales de las familias se han ido homogeneizando a pesar de que la distribución del ingreso es cada vez más desigual. En este contexto, la educación financiera es necesaria para que las personas internalicen la norma neoliberal de organizar a la sociedad chilena respecto a la forma de llegar a dichas aspiraciones a través de la deuda, y no queden excluidas.

El mecanismo concreto para el cambio en la normatividad de la deuda es paradojalmente la del empoderamiento. Así, actores financieramente racionales, que se endeudan "razonable y saludablemente" son sujetos que tienen la capacidad de la responsabilidad de su propio destino. El crédito y la deuda son herramientas públicas para que sujetos marginados o no, se sientan empoderados económicamente, al menos durante algún momento de su ciclo de endeudamiento. Ya sea para mejorar sus condiciones materiales, para realizar pequeños emprendimientos, para estudiar, para mejorar la apariencia personal o del hogar, o para comprar un lugar para vivir, la deuda se presenta como la única opción. El crédito es visto como una herramienta de integración social a lo que se percibe como sociedad de consumo. Por ejemplo, mujer, vendedora de tienda, 54, asevera que el "sistema" social actual está hecho para vivir con crédito.

"El sistema te pide vivir con crédito, yo lo veo a diario aquí en la tienda. Por ejemplo, antes salir de vacaciones era un lujo, pero ahora ir a Brasil de vacaciones se puede hacer, pero en cuotas. La gente como que se ve obligada a hacerlo, como si eso fuera la necesidad. Así es el sistema”.

El sistema sería una mezcla de exigencias sociales y la oferta de una vida mejor basada en cosas que "antes" eran una especie de lujo, como pasar unas vacaciones en Brasil, pero "ahora” son como una imposición social. Con otros matices, mujer, ejecutiva inmobiliaria, 50, comenzó a tener crédito cuando tenía 20 años. Le ofrecieron una tarjeta de crédito en la universidad y siempre se ha mantenido como usuaria del crédito para no estar al margen.

"Tenía todas las cosas financieras funcionando bien, pero tarde o temprano, la máquina me atrapó y me castigaron. Sin embargo, el próximo año, estaré limpia, y podré volver a pedir más crédito, por- 
que no se puede estar afuera de eso [el crédito], si quieres tener auto, casa, educación, cosas... cómo se vive ahora”.

Para ella, el crédito es inevitable y ayuda a dar forma a nuestras vidas.

\section{Discusión}

Como una concreción de principios de gestión y políticas públicas, el neoliberalismo es una racionalidad dirigida a conminar a los individuos a identificar sus metas individuales, a mejorar sus habilidades, a ser asertivos y a ir por más. La competencia y la responsabilidad individual dominan el paisaje social. La primitiva acumulación de diferentes tipos de capital no es relevante, sino más bien, la apariencia de un sistema donde las acciones de escoger y aspirar luzcan inevitables. Detrás de cada opción y práctica, hay, bajo estas condiciones, cálculos de costo-beneficio, acción instrumental, costo de oportunidades y el problema económico básico: la escasez. Estos ingredientes configuran un conjunto de políticas en salud, educación, vivienda, pensiones, consumo ordinario, donde la paradoja es la multiplicidad de opciones, pero inalcanzables para todos. Aún más, en ciertos mercados las opciones son una apariencia, debido a la tendencia del capitalismo chileno a funcionar en torno a oligopolios o cárteles. No obstante, su marcada diferenciación social -alrededor de 20 por ciento de las familias tiene cuenta corriente bancaria, principalmente en los deciles de mayores ingresos, mientras el 65 por ciento de las familias de ingresos bajos y moderados tienen tarjeta de retail-, el mercado del crédito es uno de los más asequibles para los chilenos de manera formal o a través de relaciones sociales -por ejemplo, pidiendo prestada la tarjeta-. A través de este eufemístico acceso, donde descansa la posibilidad de acceder o escoger. Y funciona tal que el crédito se desliga de la deuda, normalizándolo, y la gente se preocupa de pagar en tanto ello los habilita para poder seguir en el crédito, actualizando voluntariamente el mecanismo de control. La mayoría de mis entrevistados desarrolla la noción de 'activo' para referirse al crédito. Dicha noción es fundamental para unir las distintas nociones del sujeto neoliberal abrumado y emprendedor. Los activos son necesarios para lograr objetivos individuales y, para ello, debemos cumplir de manera satisfactoria los requisitos de solvencia crediticia que imponen los prestamistas. La solvencia crediticia exige autocontrol y responsabilidad. La masificación del acceso al crédito también es funcional para soslayar la falta de acumulación de capital de las capas medias y bajas, y de esta forma, fortalecer el consumo interno. Al mismo tiempo, el neoliberalismo descarga el uso del crédito en la responsabilidad individual y no en la sistémica o institucional; por tanto, quienes se adapten a ello tendrán una mejor posición que quienes no lo hagan. Las desigualdades y la pobreza, por lo tanto, se construyen en el marco neoliberal como el resultado individual de la conducta de aquellos que no son lo suficientemente inteligentes o responsables consigo mismos, incluso en su uso del crédito. En este marco, la inequidad y pobreza es fruto de quienes no son capaces de gestionarse a sí mismos, lo que incluye el crédito. 
Por otro lado, es evidente que materialmente, endeudarse es el resultado de la precariedad y la ausencia de redes de seguridad social. El vínculo del crédito con esta suerte de disimulo de la pobreza es muy distinto al sujeto endeudado que usa el crédito para contrarrestar su posible pérdida de estatus. La obligación de endeudarse es insoslayable para buena parte de los sujetos neoliberales en Chile. La obligación de pagar la deuda es material antes que moral, puesto que la solvencia crediticia es necesaria para mantener el acceso regular y sin problemas al crédito. Los deudores adoptan las reglas del crédito, intentan adaptarse a ellas, pero están conscientes de que dichas reglas no están destinadas a cuidar sus propios intereses.

La idea de una la deuda como un dispositivo de control social es antigua y precedente al advenimiento del neoliberalismo. Podemos encontrarla en los albores de la revolución industrial (Gerber, 2014) y más concretamente a propósito del New Deal estadounidense, postulando que aquellos trabajadores que deben pagar una hipotecar serían menos proclives a ejercer el derecho a huelga, y en base a aquello, entre otras cosas, se incentivó la adquisición de casas por medio de hipotecas, como un requisito sine qua non del Sueño Americano (Cohen, 2002). También en Chile, se ha teorizado en torno a aquello, un par de décadas atrás, principalmente a partir del análisis crítico de la modernización chilena, en particular, de la instalación de la llamada sociedad de consumo. La ciudadanía crediticia (Moulián, 1997, 1998) implica la subordinación de cualquier pulsión conflictiva del trabajador promedio a la continuidad de su acceso al crédito, y a través de él, a un nivel de consumo inédito tanto individual como colectivamente. Esta medida de sujeción significaba la marginación voluntaria de cualquier acción laboral conflictiva y también la voluntaria aceptación de condiciones laborales injustas, con la perspectiva de mantener o aumentar la capacidad de acceso al crédito que entrega el trabajo asalariado. A esto debemos sumar las narrativas políticas de ascenso social individual y de desprestigio de la acción política colectiva.

El crédito también aparece como un dispositivo de la "seguridad social" en términos que ayuda a proveer bienes y servicios que el Estado ya no provee o son de difícil acceso, como educación, salud, vivienda. El crédito se transforma en un activo que algunas familias usan en tanto está presente en la estructura de oportunidades; sin embargo, a la vez que es un activo puede ser también una amenaza en el sentido que el crédito genera endeudamiento, y por otra parte contribuye a darle un nuevo rostro, tal vez una nueva estética, en lo que se ha denominado la "pobreza equipada" (FSP, 2010). En este caso, se podría constatar que las habilidades financieras podrían estar presente de manera instrumental y en continua negociación con los propios saberes y marcos de significados de las familias. El crédito está vinculado a distintos niveles de las nuevas caras de la pobreza.

El discurso sobre las responsabilidades individuales y su mecanismo subjetivo de control implica mantener cuentas en orden. En el caso particular del endeudamiento, la educación financiera traduce la demanda de orden no en la ausencia de endeudamiento, sino que una presencia 
constante y "racional” de la deuda. Es lo que ha sido bautizado como "endeudamiento" saludable. La forma particular de acumulación capitalista que cimentó en el neoliberalismo chileno tiene la siguiente lógica: ciertamente, si la educación financiera se orientara a prescribir el no uso de la deuda y, digamos, el uso del ahorro habría un desequilibrio económico y de poder entre deudores y acreedores. Considerando que el sector de las grandes cadenas minoristas son los grandes proveedores de crédito, que el mismo sector ya depende en más de un 50 por ciento de su ala financiera para generar utilidades, y que dicho sector es un gran empleador, provocaría a lo menos una crisis súbita o paulatinamente, si los deudores -actuales o en potencia- "aprendieran" a ahorrar y dejaran de endeudarse. Menos utilidades, menos empleo. En ese contexto, la propuesta de la educación financiera es "aprender" a endeudarse "saludablemente".

El concepto de gubernamentalidad con énfasis en la responsabilidad individual y en la autogestión de estos consumidores financieramente competentes, se transforma en una visión que hace descansar el bienestar social sobre el bienestar de los mercados y la capacidad de optar y ser responsables de los consumidores. Los individuos deben ser cautos antes el riesgo, pero también atentos a las oportunidades que presentan los mercados. El crédito es el mejor ejemplo de cómo los individuos deben aprender a manejar las nociones de riesgo y oportunidad. Si en algún momento se conceptualizó la adquisición de bienes desde un punto de vista simbólico y social, es decir, efectos de comprarse un auto o una casa sobre nuestra “autopercepción social”, ahora se ha agregado la visión de activos lo que requiere un involucramiento financieramente más reflexivo de parte de los consumidores.

No parece apropiado reducir el sujeto endeudado a uno categoría universal. De la misma forma, parece simplista establecer una nueva lucha de clases entre deudores y acreedores, ya que, en términos de subjetividades, aquello ignoraría la heterogeneidad interna entre deudores, a saber: el grado de adopción o rechazo implícito o explícito de la normatividad neoliberal, el nivel de precariedad relativa -por ejemplo, la cantidad de ingreso mensual disponible tras pagar las deudas-, la tasa de explotación -los intereses pagados-, y la posibilidad o no de abandonar la deuda, y por cuánto tiempo. El sujeto endeudado“chilensis” es cambiante y no parece tan culposo como el Lazzarato de (2012). Por cierto, no es un deudor que ha surgido para hacer frente al abandono del estado de bienestar, y no ha sido culpado de ninguna tragedia histórica todavía. Sin embargo, este sujeto endeudado o ciudadano credit-card es considerablemente menos autónomo que el aquel sujeto prefigurado bajos las condiciones de la 'gestión-deuno-mismo'. El sujeto endeudado en Chile - y que se expande en Latinoamérica- es cercano a un trabajador del siglo XIX, acosado mental y físicamente por el panóptico, ahora encarnado en las condiciones laborales y contractuales del proletariado de servicios. Tiene, por cierto, rasgos del sujeto consumidor y emprendedor de las sociedades avanzadas que es forzado a perseguir sus intereses de manera egoísta y, al mismo tiempo, a ejercer el autocontrol. 
La economía de la deuda duplica al trabajo, en el sentido que impone un trabajo en sí mismo, al producir valor y subjetividad, al mismo tiempo. Además, el endeudamiento ubica a los sujetos no sólo bajo un control subjetivo, sino que también material. La comentada inclusión financiera es intrínsecamente una forma de incrementar el acceso a un bienestar en base a deudas, de manera opuesta a la concesión de derechos sociales. Así las cosas, no parece casual que el Estado neoliberal chileno se esforzara en orientar el sistema educacional bajo el principio del derecho a escoger, posteriormente, del derecho a "pagar por escoger", en el caso de la educación primaria y secundaria, y finalmente, en el derecho a endeudarse para estudiar, en el caso de la educación superior. En la misma línea la promesa neoliberal de que todos seríamos propietarios, accionistas y emprendedores, recogida en los discursos fundacionales y programáticos tanto de Pinochet como de Thatcher, se transformó en la 'fábrica del hombre endeudado' parafraseando al mismo Lazzarato (2012). Últimamente, es coherente que diversas agencias estatales, incluyendo el Banco Central, unan esfuerzos para implementar una estrategia unificada de Educación Financiera.

Marron (2014) enfatiza el rol de la educación financiera en la producción de sujetos responsables, cautos, calculadores y reflexivos respecto a sus asuntos financieros cotidianos. Apunta al aprendizaje del manejo financiero como una herramienta clave de los gobiernos para de hecho gobernar las conductas de sus ciudadanos. Esta gubernamentalidad (Foucault, 2005) se basa en la capacidad de los individuos de aprender a tomar riesgos y asumir responsabilidades individuales en ello. Igualmente, bajo este supuesto funciona el paradigma de la economía neoclásica que alimenta teóricamente las distintas implementaciones del neoliberalismo. A su vez, este paradigma es subsidiario de los programas de educación financiera los cuales usualmente descansa en el conocimiento experto de los agentes estatales y técnicos, y desplazan el conocimiento práctico que los jefes y jefas de hogar han acumulado en su rol de planificadores domésticos.No obstante, apartándose de la gubermentalidad, Marron propone la idea de virtualismo, concebido como el poder de las ciencias económicas de modelar y poner en la agenda social a las habilidades financieras; por ejemplo, para ajustar al consumidor 'real' a los modelos abstractos de la economía neoclásica, gracias precisamente a los programas de educación financiera (Miller, 2001).

El virtualismo sería entonces la capacidad y voluntad de gobiernos e instituciones financieras de ajustar a los hogares reales en el marco de los programas de educación financiera. No se trata aquí de la performatividad de las ciencias económicas y los mercados, sino que más bien de la prescripción de formas particulares y medibles de comportamiento financiero que los hogares deben tomar como suyas. La estrategia de educación financiera, en Chile o en cualquier lugar del mundo, usualmente presume de poseer un sólido conocimiento de sus ciudadanos crediticios y sus debilidades, y sobre esa base, es capaz de normar -no obligar- a los sujetos neoliberales ysu comportamiento en términos financieros. 
La individuación como contenido de la subjetividad neoliberal en la sociedad chilena se ha desplegado en varias dimensiones. Un primer rasgo es la visión subyacente en las políticas públicas bajo el supuesto de actores atomizados que esparcen bienestar al mismo tiempo que buscan su propio interés. Un segundo rasgo es la pérdida de centralidad de la acción colectiva, ya sean a través de sindicatos, partidos políticos o movimientos sociales. Un tercer rasgo sería la hegemonía de proyectos identitarios individuales a nivel micro, esto es, la pérdida de relevancia relativa de las ocupaciones y la clase como referencias, y el surgimiento de los estilos de vida y los procesos de movilidad individual. Más de 30 años han pasado desde que los procesos de individualización (Beck, 2000) y de decaimiento de la cohesión social se iniciaron en la sociedad chilena (Moulián, 1997). Trabajadores del comercio y similares experimentan su vida laboral de manera muy distinta a la clase obrera del siglo XX. Anonimato, rotación, dificultad de establecer vínculos sociales con sus compañeros de trabajo. En ese caso, la cohesión social sería un residuo de relaciones individuales (Schiefer yvan der Noll, 2017), y su énfasis estaría más en la aceptación del orden social que en los diversos grados de conflictividad latente y expreso a la hora de evaluar la relación entre un esfuerzo y su recompensa social. La alienación está presente, pero usualmente no hay radicalización, porque junto con la individualización, no hay interés por la sociedad, por lo poco que les ofrece (Dahrendorf, 1990).

Los contenidos normativos del modelo de desarrollo implantado en 1975 tienden a un tipo de movilidad social individual, basada en la propia iniciativa y en una personalidad emprendedora. En el plano de las relaciones laborales esto significa desorganización de los trabajadores, en un contexto en que las distintas modalidades de contrato limitan las posibilidades de la acción colectiva. Si antes la movilidad estaba dada por la negociación colectiva, acceso a la educación formal y antigüedad en el trabajo, a contar de este periodo se da principalmente en una modalidad individual. De hecho, hoy en día, se piensa que el ascenso social depende más del esfuerzo y de las estrategias de las familias, antes que de un movimiento general (Mayol, Azócar y Azócar, 2013).En el caso de Chile, al ingresar en su periodo histórico neoliberal a mediados de los 1970s, una amalgama de nuevos principios normativos fue promovida y/o introducida desde diversos flancos y dirigidos hacia vastos sectores de la sociedad. Esto se generó como un subproducto de la serie de reformas conocidas como el ajuste estructural. Estas medidas normaron el análisis de costo-beneficio económico (en la mayoría de los casos, francamente monetario) en el ámbito de las políticas públicas, pero también en el de las relaciones sociales. También proporcionaron una alta valoración a la idea de emprendimiento y a la figura del emprendedor; a la noción de competencia y a la de igualdad de oportunidades, los que a su vez nutrieron un discurso político que precisamente huía retóricamente de lo tradicionalmente político y proponía abrazar lo técnico. En este nuevo paisaje, el Estado no fue más un actor principal, no obstante, tal como indicó Polanyi (1989), el Estado es crucial para la creación de nuevos mercados y para el asentamiento formal y político del predominio de los mercados autorregulados. Además de ser achicado, se le 
despojó de cualquier rol relevante en el progreso social, en la lucha contra la pobreza o en la optimización de la distribución del ingreso y del poder. Esto minimizó el margen de acción del Estado no sólo en la esfera productiva, sino que también lo privó de su rol mediador entre sociedad y sistema político (Garretón, 2012). Aún más, la sociedad se volvió segregada y segmentada en zonas con poca comunicación.

Sin embargo, es posible replantear la pregunta por la acción colectiva, desde otra perspectiva. Por ejemplo, la visión misma del mercado autorregulado se mantiene como un espejismo en el capitalismo chileno, caracterizado por acciones de cartel y oligopolios; son precisamente dichas características de capitalismo jerárquico (Schenider, 2013) las que, al salir a la opinión pública, han motivado, por ejemplo, las demandas que se han “colectivizado” a través de Sernac, llegando a más de 11,000 personas. Actores como la ODECUS y CONADECUS -organizaciones de consumidores- han ingresado al consejo consultivo dela organización gremial Retail Financiero.En otro plano, el sitio web www.reclamos.cl goza de gran masividad, complejidad y dinamismo. Permite también vigilar a los vigilantes, puesto que registra una cantidad no menor de reclamos contra el Servicio Nacional del Consumidor. Son instancias donde además se intercambian conocimientos, puntos de vista y también se transforma lo individual en algo colectivo, cuando se identifican problemas y urgencias comunes. Hay otros hechos más anecdóticos tales como demostraciones callejeras, como las protestas iniciales contra el funcionamiento del Transantiago, y el boicot de productos, para el caso de la colusión de empresas fabricantes de papel higiénico. También desde los comportamientos económicos se pueden observar prácticas de consumo sustentable y de economía solidaria, que requieren un cierto grado de organización y pueden desembocar en un nivel de movilización. Sin duda, destaca el “movimiento” No+AFP, que apunta a cambiar del sistema de pensiones de capitalización individual, y sus características descentralizadas y de alta convocatoria pública. Deville (2016) plantea que al mezclar la política y las formas de cálculo de mercado surgen las debtor publics, es decir, la deuda privada de los hogares se hace algo público No pretende mirarlos como un emergente movimiento social, sino que más bien como un ente colectivo que, al tratar de enfrentar a organizaciones poderosas, elabora formas organizacionales potencialmente desafiantes.

El endeudamiento masivo no implica la generación de sujetos completamente individualistas, autogobernados o grandes apostadores en la “economía de casino”, sino que más bien se circunscribe a los procesos de tolerancia que las familias de bajos y moderados ingresos realizan respecto del capitalismo. Las circunstancias estructurales del capitalismo chileno y la normativización de ciertas aspiraciones completan el panorama en el cual los hogares adaptan y adoptan la financiarización de la vida cotidiana. El despliegue mismo de agencia en estas prácticas situadas resulta crucial para criticar la transformación de las familias en meros sujetos pasivos, consumistas y atomizados. 
En otros casos, el Estado y las empresas apuntan a desdibujar lo colectivo, como con la educación financiera destinada a enfatizar la responsabilidad individual de los consumidores financieros, así como en su momento se apuntó a separar los buenos de los malos deudores habitacionales.Para el caso concreto de los deudores hipotecarios, buscar una intervención estatal, como una forma de politizar la deuda, puede contradictoriamente afectar la subjetividad de los individuos, quienes han asumido una identidad más autónoma, autovalente y movilidad social... Esas formas de acción colectiva chocan con el discurso de "gente de trabajo" o strugglers. Esto puede explicar el éxito limitado de los deudores hipotecarios en Chile: entre la articulación de sujetos reclamando la vivienda como un derecho -cuestionando el neoliberalismo- y sujetos que aparecen como fallidos sujetos financieros y pobres pidiendo ayuda (Sabaté, 2016).

Chile es uno de los pocos lugares donde "el retail" (tiendas por departamento, supermercados, etc.) hace sentido como espacio social y económico. Sus empleados -que trabajan, consumen, y se endeudan con el mismo ente- forman parte de un proletariado postindustrial que no tiene la visibilidad de otros grupos más organizados y con mayor capital social, cultural o económico. Debido a lo anterior, suele quedar fuera del alcance académico y con serios problemas para constituir su identidad al carecer de referencias (Barozet yEspinoza 2016). Junto a ellos, conviven otros grupos de trabajadores como los de call centers o de comida rápida, y pequeños emprendedores, entre otros, que viven una creciente precarización de sus condiciones de trabajo, llegando incluso a ser 'trabajadores pobres', debido a sus paupérrimas situaciones, o que también entran y salen de la pobreza. Muchos de ellos se sienten parte de una 'clase' de esfuerzo, donde el discurso de la movilidad individual superó largamente a la lucha de clases (Castillo, 2009); en general, son ex pobres y aspirantes a la clase media o son parte de sus sectores bajos ${ }^{3}$. Una sección importante de la subjetividad neoliberal se trata de negociar las identidades de clase y la relación con la pobreza, a través de narrativas construidas en base ya no a categorías ocupacionales, sino que las diferencias que se extraen a partir de uso de la deuda y a condiciones materiales en base a ella.

Vastos grupos de la sociedad chilena carecen de la educación y credenciales para considerarlos grandes inversores en capital humano ${ }^{4}$. No obstante, la masificación de la educación superior en la última década aumento de un 75 por ciento de la matrícula desde 2005- da cuenta de la normalización de la instrumentalización de la educación como un medio para la satisfacción de aspiraciones. No parece casual que en el 60 por ciento de los casos dicha aspiración deba actualizarse a través de la deuda. Para aquellos que por edad o por su margen de acción no pudieron adscribirse a la exigencia de capital humano, existen otras instancias de sujeción y control que pueden yuxtaponerse: educación financiera, endeudamiento por consumo ordinario, emprendimientos de baja calificación por falta de oportunidades en el mercado laboral formal.

La deuda es crucial para la producción del sujeto neoliberal que debe 
asumir indeleblemente su existencia con el único recurso a mano del crédito o estar condenado a la miseria. Postulamos aquí que tanto la normatividad de las aspiraciones en su acepción más mínima, como el medio para conseguirlas, son ofrecidos como un 'mal obligatoriamente necesario' por el entramado neoliberal e incorporados a la subjetividad de aquellos quienes lidian con el crédito en su vida diaria, en la búsqueda una 'vida decente'. La deuda conecta la dimensión sistémica del capitalismo contemporáneo con las prácticas de la vida diaria, en tanto dispositivo de control y captura. La obligación de pagar involucra la necesidad de neutralizar y auto controlar alternativas a la financiarización.

\section{Agradecimientos}

El autor desea agradecer el financiamiento a Becas Chile y al Centro de Estudios del Conflicto y la Cohesión Social [FONDAP 15130009]. 


\section{Notas}

${ }^{1}$ Fuente: talleres Fosis, cursos en línea para profesores del Sernac, talleres y material visual SBIF, material de divulgación del Banco Central, entrevistas con encargados de Educación Financiera de agencias estatales

${ }^{2}$ Fuente: entrevistas con jefes y jefas de hogar.

${ }^{1}$ De acuerdo a distintas discusiones, es un grupo que bien podría ser considerado parte del precariado típico del capitalismo financiero (Standing, 2011) o de la 'nueva' clase media.

${ }^{2}$ No obstante, se señala que ya en los 1990s, cambios culturales asociados a la masificación de la sociedad de mercado: como resaltábamos, individuos que esperan poco del Estado y de la acción colectiva organizada, y más bien confían en ellos mismos, por lo que toman más riesgos y su estrategia principal es la inversión en capital humano (Torche y Wormald, 2004;Tironi, 2003). 


\section{Bibliografía}

Barros, M. (2011). Prácticas financieras en torno al uso del crédito en la industria. En J. Ossandón (Ed.), Destapando la Caja Negra: Sociologías de los créditos de consumo en Chile. Santiago, Chile: Instituto de Investigaciones en Ciencias Sociales, ICSO.

Barry, A., yOsborne, T. (Eds.). (2013). Foucault and Political Reason: liberalism, neo-liberalism and the rationalities of government. Londres, Inglaterra: Routledge.

Beck, U. (2000). La democracia y sus enemigos (No. 321.8 B391d). Barcelona, España: Paidós.

Cohen, L. (2004). A Consumers’ Republic: The Politics of Mass Consumption in Postwar America. New York, Estados Unidos: Vintage.

Dahrendorf, R. (1990). El con?icto social moderno. Madrid, España: Ed. Mondadori

Denegri, M., Del Valle, R., González, Y., Etchebarne, L., Sepúlveda, J., ySandoval, D. (2014). ¿Consumidores o ciudadanos?: Una propuesta de inserción de la educación económica y financiera en la formación inicial docente. Estudiospedagógicos (Valdivia), 40(1), 75-96.

Deville, J. (2016). Debtor publics: tracking the participatory politics of consumer credit. Consumption Markets \& Culture, 19(1), 38-55.

French-Davis, R. (2003). Entre el neoliberalismo y el crecimiento con equidad: tres décadas de política económica en Chile. Santiago, Chile: JC Sáez Editor.

Foucault, M. (1991). The Foucault effect: Studies in governmentality. Chicago, EstadosUnidos: University of Chicago Press.

Foucault, M. (2005). La hermenéuticadelsujeto.Cursos Del College De France, 1981-1982 (Vol. 237). Madrid, España: Ediciones Akal.

French, S., Leyshon, A., yWainwright, T. (2011). Financializing space, spacing financialization. Progress in human geography, 35(6), 798819.

Fundación de Superación de la Pobreza (2010). Voces de la pobreza. Santiago, Chile: FSP.

Garretón, M. A. (2012) Neoliberalismo corregido y progresismo limitado. Los gobiernos de la Concertación en Chile, 1990-2010. Santiago, Chile: Arcis/Clacso. 
Gerber, J. F. (2014). The role of rural indebtedness in the evolution of capitalism. Journal of Peasant Studies, 41(5), 729-747.

Gonzalez, F. (2015). Where are the Consumers? Cultural Studies, 29(5-6), 781-806. doi:10.1080/09502386.2015.1017144

González, F. (2017). Privatized Keynesianism or Conspicuous Consumption? Status Anxiety and the Financialization of Consumption in Chile. Köln, Germany: Max-PlanckInstitutfürGesellschaftsforschung.

Lazzarato, M. (2012). The Making of the Indebted Man: An Essay on the Neoliberal Condition. Los Angeles, EstadosUnidos: Semiotext(e).

Marambio-Tapia, A. (2018). Narratives of Social Mobility in the PostIndustrial Working Class and the Use of Credit in Chilean Households. Revue de la Régulation-Capitalisme, institutions, pouvoirs, 22.

Marron, D. (2014). Informed, educated and more confident: financial capability and the problematization of personal finance consumption. Consumption Markets \& Culture, 17(5), 491-511.

Martin, R. (2002). Financialisation of Daily Life. Philadelphia, EstadosUnidos: Temple University Press

Mayol, A., Azócar, C., \&Azócar, C. (2013). El Chile Profundo. Modelos Culturales De La Desigualdad y Sus Resistencias.Santiago, Chile: LiberaliaEdiciones.

Miliband, R. (1987). Class analysis. Social theory today, 325-46.

Miller, D. (2001). The poverty of morality. Journal of consumer culture, 1(2), 225-243.

Moulian, T. (1997). Chile: Anatomía de un mito. Santiago, Chile: Lom.

Moulian, T. (1998). El consumo me consume. Santiago, Chile: Lom.

Müller, L. (2014). Negotiating debts and gifts: financialization policies and the economic experiences of low-income social groups in Brazil. Vibrant: Virtual BrazilianAnthropology, 11(1), 191-221.

Muñoz, O. (2007). El modelo económico de la concertación 1990-2005:¿ reformas o cambio?.Santiago, Chile:Flacso.

OCDE (2014) National Strategies for Financial Education: OECD/INFE Policy Handbook 
Ossandón, J. (2013). Sowing consumers in the garden of mass retailing in Chile. ConsumptionMarkets \& Culture, 1-19. doi:10.1080/ 10253866.2013.849591

Ossandón, J., Ariztía, T., Barros, M., y Peralta, C. (2017). Contabilidad en los márgenes: ecologías financieras entre big y small.Revista Crítica de CiênciasSociais17(1), 26. doi:10.15448/1984-7289.2017.1.25021

Peck, J. (2004). Geography and public policy: constructions of neoliberalism. Progress in Human Geography, 28(3), 392-405.

Perez-Roa, L. (2014). The real weight of college loans. The issue of young debtors of the Corfo undergraduate school loan in Santiago de Chile., 22. doi:10.14507/epaa.v22n75.2014

Polanyi, K. (1989). La Gran Transformación. Madrid, España: La Piqueta.

Sabaté, I. (2016). The Spanish mortgage crisis and the re-emergence of moral economies in uncertain times. History and anthropology, 27(1), 107-120.

Schiefer, D., y van der Noll, J. (2017). The essentials of social cohesion: A literature review. Social Indicators Research, 132(2), 579-603.

Schneider, B. R. (2013). Hierarchical Capitalism in Latin America. Cambridge, Inglaterra:UniversityPress.

Weber, M. (2012). Historia económica general. México D.F, México: Fondo de cultura económica.

Recibido: 22.01 .18

Aceptado: 10.04 .18 